\title{
LARYNGOLOGY
}

\section{Endoscopic cauterisation and injection of Voicegel for treatment of congenital pyriform fossa sinus tracts}

\author{
Trattamento delle fistole congenite del seno piriforme mediante cauterizzazione \\ endoscopica e iniezione di Voicegel
}

\author{
Roy Hod',2, Sophie Lachance ${ }^{2,3}$, Neil K. Chadha ${ }^{2,4}$ \\ ${ }^{1}$ Department of Pediatric Otolaryngology, Schneider Children's Medical Center of Israel, Petach Tiqwa, Israel; ${ }^{2}$ Division of Pediatric \\ Otolaryngology-Head and Neck Surgery, BC Children's Hospital, Vancouver, British Columbia, Canada; ${ }^{3}$ Département d'Oto-rhino- \\ laryngologie et chirurgie cervico-faciale, CHUL, CHU de Québec, Québec, Canada; ${ }^{4}$ University of British Columbia, Vancouver, \\ British Columbia, Canada
}

\begin{abstract}
SUMMARY
Objective. To demonstrate our experience in treating pyriform fossa sinus tracts (PFST) using a novel technique of endoscopic cauterisation of the pyriform fossa sinus opening combined with injection of sodium carboxymethylcellulose gel (VoiceGel) lateral to the tract to encourage tight closure.

Methods. Over a 48-month period, we used this technique on 11 patients who were diagnosed with PFST at BC Children's Hospital, a tertiary paediatric centre in Vancouver, BC, Canada. Results. The 11 patients included 8 males and 3 females, and mean age at presentation was 69 months (range 22-108 months). Mean time from beginning of symptoms till diagnosis was 15 months (range 12-22 months). Ten PFST were on the left side of the neck and one on the right. Nine patients presented with recurrent neck infections and two had suppurative thyroiditis. All patients had endoscopic cauterisation of their PFST opening combined with injection of carboxymethylcellulose lateral to the sinus tract to cause tract collapse. Mean follow up was 15.8 months (range 8-24). All patients are asymptomatic without recurrence at the last follow-up visit. No post-operative complications were reported.

Conclusions. Endoscopic management of paediatric PFST combined with the injection of sodium carboxymethylcellulose gel lateral to the sinus tract appears to be a safe and effective treatment option for PFST.
\end{abstract}

KEY WORDS: piriform fossa sinus tract, endoscopy, cauterisation, carboxymethylcellulose

\section{RIASSUNTO}

Obiettivo. Descrivere la nostra esperienza nel trattamento delle fistole congenite del seno piriforme (PFST) utilizzando una nuova tecnica di cauterizzazione endoscopica del seno piriforme ed iniezione di gel di sodio carbossimetilcellulosa (VoiceGel) per favorire la chiusura del tramite. Metodi. Per un periodo di 48 mesi, abbiamo utilizzato questa tecnica su undici bambini a cui è stata diagnosticata la PFST al BC Children's Hospital, un centro pediatrico terziario di Vancouver, BC, Canada.

Risultati. Il gruppo di bambini includeva 8 maschi e 3 femmine, l'età media era di 69 mesi (range 22-108 mesi). Il tempo medio dall'inizio dei sintomi fino alla diagnosi è stato di 15 mesi (range 12-22 mesi). Dieci PFST erano sul lato sinistro del collo e uno a destra. 9 pazienti soffrivano di infezioni ricorrenti del collo e due avevano tiroidite suppurativa. Tutti i pazienti sono stati trattati mediante cauterizzazione endoscopica ed iniezione di carbossimetilcellulosa per cicatrizzare il tratto fistoloso. Il follow-up medio è stato di 15,8 mesi (range 8-24). Tutti i pazienti sono asintomatici, senza recidive al follow-up. Non sono state riportate complicanze postoperatorie.

Conclusioni. Il trattamento endoscopico della PFST pediatrica combinata con l'iniezione di gel di carbossimetilcellulosa di sodio sembra essere un'opzione terapeutica sicura ed efficace per le PFST.

PAROLE CHIAVE: seno piriforme, fistole del seno piriforme, endoscopia, cauterizzazione, carbossimetilcellulosa
Received: January 31, 2021

Accepted: April 15, 2021

Correspondence

Roy R. Hod

Department of Pediatric Otolaryngology-Head and Neck Surgery, Schneider Children's Medical Center of Israel, 16 Kaplan Street, Petach Tiqwa, 49300 Israel

Tel. +97239253367

E-mail: royhod@gmail.com

Funding

None.

Conflict of interest

The Authors declare no conflict of interest.

How to cite this article: Hod R, Lachance S, Chadha NK. Endoscopic cauterisation and injection of Voicegel for treatment of congenital pyriform fossa sinus tracts. Acta Otorhinolaryngol Ital 2021;41:432-435. https://doi. org/10.14639/0392-100X-N1433

(c) Società Italiana di Otorinolaringoiatria e Chirurgia Cervico-Facciale

\section{cc)(i) $\odot$}

This is an open access article distributed in accordance with the CC-BY-NC-ND (Creative Commons Attribution-NonCommercial-NoDerivatives 4.0 International) license. The article can be used by giving appropriate credit and mentioning the license, but only for non-commercial purposes and only in the original version. For further information: https:// creativecommons.org/licenses/by-nc-nd/4.0/deed.en 


\section{Introduction}

Piriform Fossa Sinus Tracts (PFST) are unusual anomalies thought to be of branchial pouch origin. They were first described in 1972 by Sandborn and Shafer ${ }^{1}$. They account for less than $2 \%$ of all branchial arch defects ${ }^{2}$. Most of the literature suggests that they are remnants of the third and fourth branchial pouches ${ }^{3-5}$. The pouch of origin is determined by the relationship of the tract to the superior laryngeal nerve: if it passes superior to the nerve a third pouch is suspected, whereas if it lies between the superior and recurrent laryngeal nerves a fourth pouch is implied ${ }^{3}$. It is difficult to clinically differentiate between third and fourth branchial pouch remnants, even on surgical exploration. An internal opening, usually in the left piriform fossa, is a fairly constant feature of both; thus, the term piriform fossa sinus tract is preferred ${ }^{6}$. It usually presents as recurrent deep neck infections or suppurative thyroiditis, as the tract often ends in one of the thyroid lobes. It is thought that seepage of pharyngeal content into the tract is what leads to suppuration in the neck.

PFST present most commonly in the paediatric population and are overwhelmingly more prevalent on the left than on the right ${ }^{4}$. Patients will often have had multiple infective exacerbations and/or emergency incision and drainage procedures before a definitive diagnosis is made.

Computed tomography (CT) and magnetic resonance imaging (MRI) showing an inflammatory neck mass closely associated with the thyroid can aid in diagnosis and determining the extent of the lesion. Barium contrast swallow study can also give information regarding a diagnosis of PFST with a positive predictive value of $100 \%$. Direct laryngoscopy of the pyriform fossa plays an integral role in conclusive diagnosis and should always be conducted when a PFST is suspected.

Although the presentation and methods of investigating PFST have been well described, their treatment remains controversial. Traditionally, complete open excision of the sinus tract with or without hemithyroidectomy has been advocated in order to prevent recurrence ${ }^{7-9}$. This can be technically challenging, however, with a significant risk of damage to neurovascular structures, especially in a neck previously exposed to multiple inflammatory episodes as a consequence of repeated infection and/or drainage procedures. Moreover, recurrent suppuration may still occur even after extensive surgery ${ }^{10}$.

With time, it has became apparent that recognising and addressing the internal opening helped in successful open surgical management and guiding the dissection ${ }^{1}$. An alternative approach to management, originally reported by Jordan et al. ${ }^{11}$ is ablation of the internal opening of the sinus tract in the piriform fossa via an endoscopic approach. It is thought that by closing the opening in the piriform fossa, the source of infection will effectively be cut off. This permits avoiding the need for an open procedure altogether ${ }^{10}$. Our aim was to present our initial experience of eleven patients with PFST who were treated by endoscopic electro-cautery combined with injection of sodium carboxymethylcellulose gel (Voicegel) lateral to the sinus tract. This appears to be a safe and effective technique with excellent results. To the best of our knowledge, this technique has not been previously described in the literature.

\section{Materials and methods}

Between 2013-2017 we diagnosed and treated 11 patients with PFST using the described surgical technique. For all 11 patients this was the primary treatment. There were 8 males and three females. Mean age at presentation was 69 months (range 22-108 months). Mean time from beginning of symptoms until diagnosis was 15 months (12-22). Ten PFST were on the left side of the neck and one on the right. Nine patients had presented with recurrent neck infections, and the remaining two had suppurative thyroiditis. All patients underwent the described endoscopic cauterisation of their PFST opening combined with injection of sodium carboxymethycellulose lateral to the sinus tract to cause its collapse. Mean follow-up was 15.8 months (8-24), all patients are asymptomatic at last follow up visit. No postoperative complications were reported.

The study protocol was approved by the Ethics Committee of BC Children's hospital and was carried out in accordance with the principles of the Declaration of Helsinki (approval process: 12876 ).

\section{Surgical technique}

All surgical procedures were performed under general anaesthesia and after informed consent was obtained. The patient was taken to the operating room and was placed in the supine position for intravenous induction of general, spontaneous ventilation anaesthesia by the anesthesiologist. Topical lidocaine 2\% was then sprayed (according to the patient's weight) on the larynx via a Miller laryngoscope in order to prevent laryngospasm. Dental protection was used. Once adequate depth of anaesthesia was obtained, a direct laryngoscopy and examination of the hypopharynx with a $0^{\circ}, 4-\mathrm{mm}$, Hopkins-rod telescope (Karl Storz Endoskope, Tuttlingen, Germany) was performed to try and identify the internal opening of the piriform sinus tract. If the sinus opening was confirmed (Fig. 1), suspension laryngoscopy with an appropriate-sized Parsons laryngoscope was performed (Karl Storz Endoskope, Tuttlingen, 


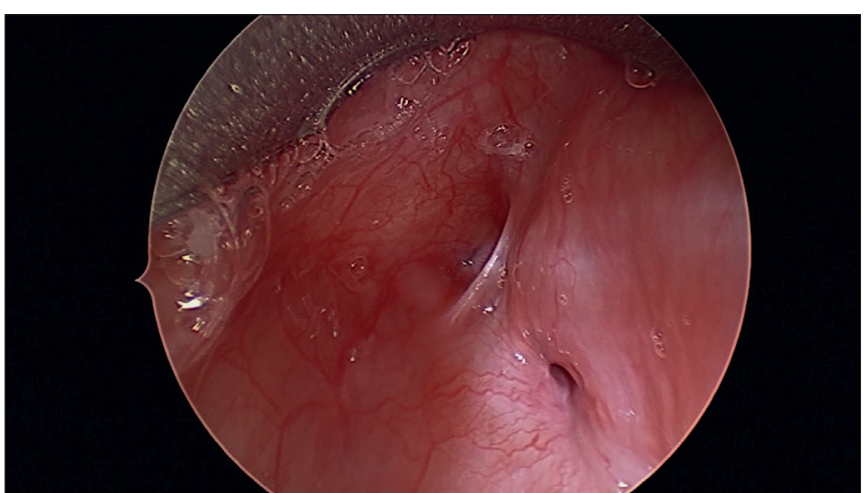

Figure 1. Piriform fossa sinus opening before cauterisation.

Germany). A 3 French Bugbee monopolar cautery (Richard Wolf, Vernon Hills, Illinois, USA) is then advanced into the opening and tract to try and measure its depth. After measuring the depth, the same tip is again advanced into the opening and coagulation starts on $5 \mathrm{~W}$ and increased if necessary. Cauterisation is performed starting from deep to superficial finishing by cauterising the opening of the sinus itself (Fig. 2). Subsequently, 0.5-1 CC of sodium carboxymethylcellulose aqueous gel (Radiesse Voice Gel; Bioform Medical Inc, San Mateo, California, USA) is injected using the provided laryngeal syringe and needle, just lateral and anterior to the PFST opening in order to make the tract collapse (Fig. 3). The injection is performed to pull the tissue around the piriform opening causing the tract to collapse, so the newly de-epithelialised tract is more likely to scar closed, as opposed to remaining as a tubular opening allowing gradual re-epithelialisation. At the end of the injection, a neuropatty with epinephrine is temporarily placed on the PFST opening for haemostasis, and once achieved removed before the patient is awakened. The patient can be discharged on the same day with a prescription of one week of oral antibiotic therapy, a recommendation of a soft diet and avoidance of the Valsalva manoeuver.

\section{Discussion}

Suppurative thyroiditis and recurrent lateral neck infections are uncommon conditions in the paediatric age group and should arouse suspicion of a piriform fossa sinus tract ${ }^{4}$. The literature suggests that some patients can remain asymptomatic for many years, often leading to misdiagnosis at initial presentation.

Previous studies have emphasised the need for direct visualisation of the internal opening of the tract to confirm the diagnosis ${ }^{1-4}$. Barium swallows are part of the diagnostic work-up, but are unlikely to show the tract until the acute event has subsided. Most authors recommend waiting 4-6

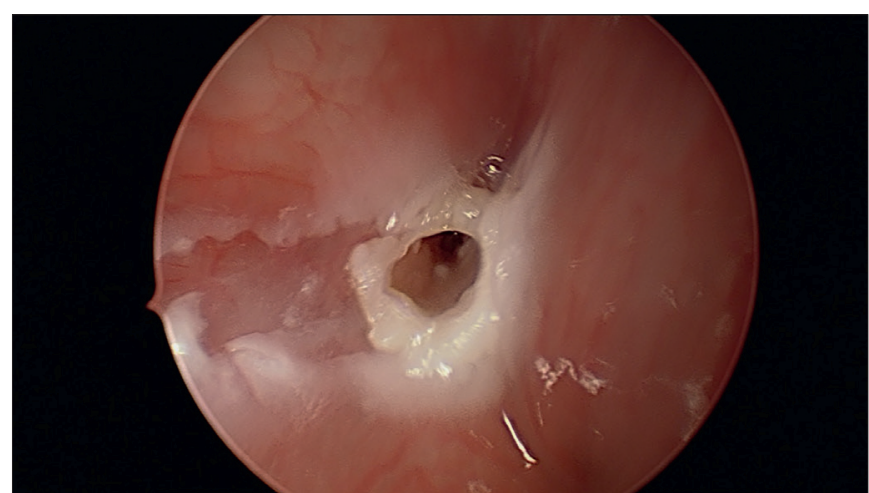

Figure 2. Piriform fossa sinus opening post cauterisation.

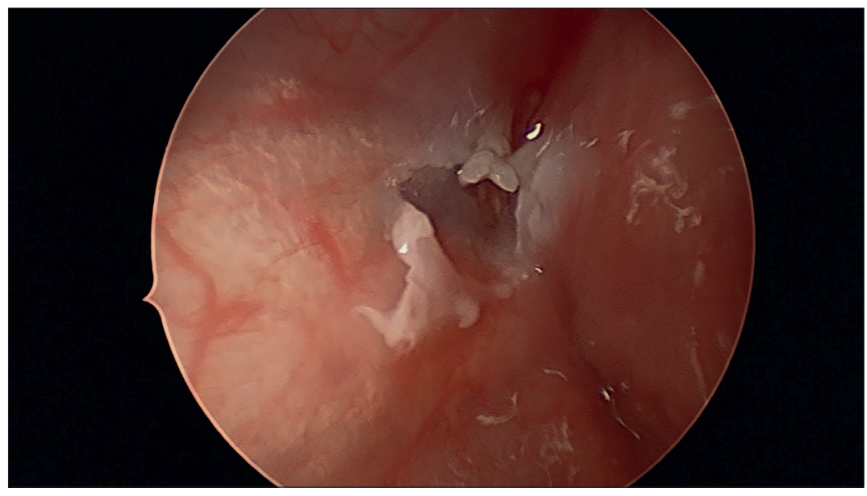

Figure 3. Piriform fossa sinus opening post cauterisation and injection.

weeks after initial presentation prior to getting the study. Although a positive barium swallow study will confirm the diagnosis, a negative one will not rule it out and requires direct endoscopic examination of the hypopharynx if the index of suspicion is high ${ }^{5}$. CT and MRI scans can depict inflammatory infiltration or an abscess along the course of the sinus tract from the piriform fossa to the thyroid gland, but are not used as a standard diagnostic tool ${ }^{6}$. Complete surgical excision of the tract has been the standard treatment in the literature. Intraoperative rigid hypopharyngoscopy can facilitate ligation of the tract in the pharynx. Thyroid lobectomy with isthmectomy is controversial, but is recommended to assist with preservation of the recurrent laryngeal nerve and to reduce the risk of recurrence when involved thyroid tissue is removed ${ }^{7-9}$. Care must be taken to avoid injury to the recurrent laryngeal nerve, which may be difficult to identify due to scarring from prior infections and operative procedures ${ }^{4}$. Other surgical modalities, such as aspiration or incision and drainage, have been shown to have increased risk of recurrence and complications such as haemorrhage, wound infection, cranial nerve injury and airway obstruction. A study by Jordan suggested that the 
piriform sinus tract partially obliterates itself following an acute infection ${ }^{10}$. In their series and subsequent follow-up evaluation, it was found that endoscopic electro-cauterisation was an effective alternative to open excision, with no patients having a recurrence of a neck mass ${ }^{10,11}$. Other endoscopic methods of tract closure have been described, such as chemical cautery using trichloroacetic acid, sealing with fibrin glue and laser coagulation ${ }^{8-10}$.

Endoscopic approaches offer many advantages over open procedures, including decreased risk to the laryngeal nerves, oesophagus, trachea and large vessels (internal jugular vein and carotid artery).

Although the results after endoscopic cauterisation appear to be promising, complete closure of the tract after the procedure has not been documented in previous studies. We assume that after endoscopic cauterisation the tract undergoes fibrosis and therefore shuts down. This technique, on some occasions, may recur due to re-epithelialisation of the tract if not completely collapsed. With our new technique, the injection of Raidesse Voicelgel just lateral and anterior to the sinus tract opening after cauterisation causes the collapse of the sinus tract walls. This ensures that when fibrosis occurs, the tract walls will fuse and create better closure of the sinus with less chances of recurrence. In our series of 11 patients, we did not have any recurrence with a mean follow-up of 15 months (8-24 months). We injected lateral and not medial to the tract in order to avoid injection into the oesophagus or large vessels.

Our report is the first to describe the use of Radiesse VoiceGel injection after electrical cauterisation for the treatment of PFST. Radiesse VoiceGel is readily available and we documented successful closure of the tract after surgery.

\section{Conclusions}

Regardless of their embryologic origin, Pyriform Fossa Sinus Tracts (PFST) have become increasingly reported in recent years. This emphasises the importance of their consideration by clinicians dealing with recurrent neck infections, especially those located on the left side of the neck. There are various options of treatment of PFST mainly grouped as open or endoscopic. Endoscopic management of paediatric PFST and injection of Radiesse Voicegel lateral to the sinus tract appears to be safe and effective. The ease of this endoscopic management of piriform fossa sinus tracts combined with the low associated morbidity make it relatively easy to recommend. As with open excision, recurrence can occur.

There are a few limitations to our study, the study population is small and the follow-up period is short (mean 15 months), although we would expect recurrence to occur shortly after the surgical procedure.

Based on our limited preliminary experience, this appears to be a very safe and effective way of dealing with these anomalous tracts of the piriform fossa.

\section{References}

1 Sandborn WD, Shafer AD. A branchial cleft cyst of fourth pouch origin. J Ped Surg 1972;7:82. https://doi.org/10.1016/j.jpedsurg.2008.12.001

2 Ford GR, Balakrishnan A, Evans JN, et al. Branchial cleft and pouch anomalies. J Laryng and Otol 1992;106:137. https://doi.org/10.1017/ S0022215100118900

3 Pereira KD, Davies JN. Piriform sinus tracts in children Arch Otolaryngol Head Neck Surg 2006;132;1119-1121. https://doi.org/10.1001/ archotol.132.10.1119

4 Verret DJ, McClay J, Murray A, et al. Endoscopic cauterization of fourth branchial cleft sinus tracts. Arch Otolaryngol Head Neck Surg 2004;130:465-468. https://doi.org/10.1001/archotol.130.4.465

5 Mandell DL. Head and neck anomalies related to the branchial apparatus. Otolaryngol Clin North Am 2000;33:1309-1332. https://doi. org/10.1016/S0030-6665(05)70283-8

6 Kim KH, Sung MW, Roh JL, et al. Sclerotherapy for congenital lesions in the head and neck. Otolaryngol Head Neck Surg 2004;131:307316. https://doi.org/10.1016/j.otohns.2004.02.018

7 Yang C, Cohen J, Everts E, et al. Fourth branchial arch sinus: clinical presentation, diagnostic workup, and surgical treatment. Laryngoscope 1999;109:442-446. https://doi. org/10.1097/00005537-199903000-00019

8 Godin MS, Kearns DB, Pransky SM, et al. Fourth branchial pouch sinus: principles of diagnosis and management. Laryngoscope 1990;100:174178. https://doi.org/10.1288/00005537-199002000-00012

9 Agaton-Bonilla FC, Gay-Escoda C. Diagnosis and treatment of branchial cleft cysts and fistulae. A retrospective study of 183 patients. Intern J Oral Maxillofacial Surg 1996;25:449-452. https://doi. org/10.1016/S0901-5027(96)80081-6

10 Lachance S, Chadha N. Systematic review of endoscopic obliteration techniques for managing congenital piriform fossa sinus tracts in children. Otolaryngol Head Neck Surg 2016;154:241-246. https://doi. org/10.1177/0194599815613286

11 Jordan JA, Graves JE, Manning SC, MD, et al. Endoscopic cauterization for treatment of fourth branchial cleft sinuses. Arch Otolaryngol Head Neck Surg 1998;124:1021-1024. https://doi:10.1001/ archotol.124.9.1021 